\title{
Empirical method for structural damage location using dynamic analysis
}

\section{Método empírico para localização de danos estruturais por meio de análise dinâmica}

\author{
R. L. SILVA \\ rodjbass@gmail.com \\ https://orcid.org/0000-0002-0533-0768 \\ L. M. TRAUTWEIN \\ leandromt@gmail.com \\ https://orcid.org/0000-0002-4631-9290 \\ C. S. BARBOSA b \\ https://orcid.org/0000-0002-5906-7547 \\ L. C. ALMEIDA a \\ almeida@fec.unicamp.br \\ https://orcid.org/0000-0001-8431-8929 \\ G. H. SIQUEIRA a \\ siqueira@fec.unicamp.br \\ https://orcid.org/0000-0002-2416-1701
}

\begin{abstract}
This paper presents the use of numerical model techniques for identification and damage location adopting the Modal Curvature Difference (MCD) method as reference for the analysis of a simply supported concrete structure. Then, an empirical formulation to detect damages in this structure is proposed. In this method, called Acceleration Summation Difference (ASD), the difference of acceleration amplitude between intact and damaged structures are calculated for concrete plates simply supported on rubber bearings. During the analyses, the finite element models were developed using SAP $2000^{\circledR}$ software. The results obtained depicted that it is possible to determine the approximate position of one or more damages in the structure, with some restrictions, and the proposed ASD method presented good correlation to localize the position of single or multiple damages.
\end{abstract}

Keywords: damage identification and location, dynamic analysis, concrete structures, numerical model.

\section{Resumo}

Este trabalho apresenta a utilização e proposição de técnica de identificação e localização de danos, por meio de modelos numéricos, adotando-se o método de localização de danos por meio da Diferença de Curvatura Modal (DCM) como referência para análise de uma estrutura de concreto biapoiada. Em seguida, apresenta-se uma proposta de formulação empírica capaz de localizar danos nesta estrutura. Neste método, denominado Diferença das Somatórias das Acelerações (DSA), calcula-se a diferença das amplitudes de aceleração em estruturas íntegras e com dano, representadas por placas de concreto sobre apoios de borracha nas extremidades. O modelo numérico foi elaborado com auxílio do pacote computacional em Elementos Finitos SAP2000 ${ }^{\circledR}$. Por meio destas técnicas conclui-se que é possível determinar a posição aproximada de um ou mais danos, com algumas restrições, tendo o método proposto (DSA), baseado na alteração da amplitude de aceleração, apresentando bons resultados na localização de um único dano e de múltiplos danos.

Palavras-chave: identificação e localização danos, análise dinâmica, estruturas de concreto, modelo numérico. 


\section{Introduction}

The identification of the structural integrity using dynamic non-destructive tests is a prominent technique due to the short time required for the field tests and lower cost, as well as the reduction of uncertainties and the possibility of repeating the method, allowing the monitoring of the structural integrity over time, evaluating the change in dynamic properties. This technique permits a planning of recovery interventions, avoiding the progression of pathological manifestations. The verification of the structural integrity, through the dynamic experimental analysis, is linked to the variation of the dynamic parameters (natural frequencies, modes of vibration and damping), directly connected to the mass and stiffness (inertia and modulus of elasticity), being possible to identify some kind of change in the structural properties punctually or over time.

Considering large constructions, especially, the importance of this methodology is emphasized, since non-destructive tests are indispensable to the practices of inspection for the maintenance of these structures, both for its economic aspect and for its reliability, allowing the identification of damages as soon as possible. Thinking about infrastructure works, their interdiction or collapse directly affects economic and social activities.

This study presents the use of a methodology for identification and location of damages, the Modal Curvature Difference (MCD), already proposed in the technical literature, in order to apply and analyze it in a Finite Element numerical model. The main objective is to propose an alternative methodology, simplified, for locating structural damage, based on the changes of parameters extracted from a possible dynamic monitoring (natural frequencies, amplitude and modes of vibration), validating it through these numerical simulations.

Nóbrega [1] defines modal analysis as the process consisting of theoretical and experimental strategies that allow the construction of a mathematical model representing the dynamic behavior of the system under study, in order to determine its modal parameters (natural frequencies, vibration modes and modal damping factors). Such parameters are often determined using analytical methods, for example, using the Finite Element Method. In other situations, the analytical model does not even exist; thus, modal parameters should be determined experimentally. Or, even if it exists, the experimental approach can be used to verify and validate the results of the analytical model.

In the opposite of theoretical analysis methodology, the experimental analysis begins with the measurement of the structure response in terms of FRFs, FRIs or variations $h(t)$. Subsequently, methods are applied to deduce the natural frequencies $(\omega)$, vibration modes $(\Phi)$ and damping factors $(\xi)$. Using appropriate techniques, or by comparison with numerical models, it is possible to deduce the spatial properties ( $M$, $\mathrm{C}$ and $\mathrm{K}$ ), but the success depends on the correct evaluation of errors and precisions.

The basic premise of damage characterization, that is, its identification and location through dynamic experimental analysis, is that the damage will significantly alter the stiffness, mass or energy dissipation properties of a system, which in turn, will change the measured dynamic response of that system (Sohn et al [2]). While the basis for damage detection seems intuitive, its actual application poses many significant technical challenges. The main challenge lies in the fact that damage is typically a local phenomenon and may not significantly influence the lower frequencies of structures, which are predominantly measured during vibration tests. Rytter [3] presented a classification for damages identification composed of four levels:

- Level 1 - Detection: Is there structural damage or not?

Level 2 - Location: Where is the damage located?

- Level 3 - Quantification: What is the severity of deterioration of the structure?

Level 4 - Forecast: What is the service life of the structure? According to Adams [4], the first level of identification originates from changes in the physical properties of the material, structural components or localized damage, and can be identified by variation of various parameters. The case studies presented in this work focus on the use of vibration and wave propagation measurements to monitor structural integrity.

In agreement with Peeters [5], there are two approaches that allow the damage identification, which is basically related to the detection of changes in dynamic characteristics, such as natural frequencies of the structure. In the first approach, a large number of sensors is used to allow the location of damage. This procedure is based on the detection of locally change in mode shapes. The location accuracy is generally limited by the spatial resolution of the measurement mesh. The second approach requires fewer sensors but needs a numerical model of the structure. The parameters of this model, which are related to the damages, are calibrated so that the dynamic characteristics of the numerical model correspond to the measurements made in the experimental model.

In addition to the damage detection, its location and quantification are points of great interest, allowing analysis with greater precision as to the durability of the structure.

The great majority of the works on damage identification use the change in frequency as indicator of structural damage. The natural frequencies of structures depend fundamentally on their stiffness and mass. Considering the mass of the structure as a known variable, it is assumed that the natural frequency variation is related to changes in stiffness, for example in reducing the cross section in a cracked beam (Doebling et al [6]).

Damping is mentioned as a potential damage identifier in some works, however, it is still a parameter with limited use in academic publications. According to Rytter [3], structures with damage will exhibit changes in damping capacity. Rytter [3] concludes that damping is applicable and recommended as a parameter to identify damages, but it should not be used alone as a single indicator.

One of the consecrated methods of damage identification is called MAC (modal assurance criterion) presented by Allemang and Brown [7], which takes into account the changes in 
the derivatives of modal deformations in the damage region, that is, the change in vibration modes.

This method compares the experimental modal vectors of the intact and damaged models. The MAC coefficient is obtained by means of Equation 1.

$$
\boldsymbol{M A C}_{(i, j)}=\frac{\left|\left\{\boldsymbol{\Phi}_{i}^{a}\right\}^{T}\left\{\boldsymbol{\Phi}_{i}^{e}\right\}\right|^{2}}{\left(\left\{\boldsymbol{\Phi}_{i}^{a}\right\}^{T}\left\{\boldsymbol{\Phi}_{i}^{a}\right\}\right)\left(\left\{\boldsymbol{\Phi}_{j}^{e}\right\}^{T}\left\{\boldsymbol{\Phi}_{j}^{e}\right\}\right)}
$$

Where:

$\left\{\Phi_{i}^{\mathrm{a}}\right\}$ - modal vector of the intact model of the i-th mode;

$\left\{\Phi_{j}^{\mathrm{e}}\right\}$ - modal vector of the damaged model of the the j-th mode.

The MAC coefficient correlates the pairs of modal vectors and its value varies between 0 and 1 . When MAC is equal to 1 it means that the modal vectors are identical and have a good correlation. On the other hand, when the MAC coefficient is equal to 0 means that the modal vectors are orthogonal to each other, with no correlation.

Most of the potential uses of the MAC are well known, but there are some less used ones. Allemang [8] presents a list of the most typical uses that have been reported in the literature, some of them are:

- Validation of experimental modal models;

- Modal correlation between analytical models;

- Modal vector error analysis;

- Weighting for updating model algorithms;

- Structural fault/damage detection;

- Quality control assessments;

- Optimization of sensor positioning.

Another technique used is called COMAC (coordinate modal assurance criterion), presented by Lieven and Ewins [9]. It correlates two modal vectors for each degree of freedom, where one of them is the reference condition. The COMAC coefficient can be defined as an extension of the MAC coefficient, identifying which degrees of freedom measured contribute negatively to a low MAC coefficient. The COMAC coefficient is obtained by means of Equation 2.

$\operatorname{COMAC}_{(j)}=\frac{\left(\sum_{i=1}^{n}\left\{\boldsymbol{\Phi}_{i}^{a}\right\}_{j}\left\{\boldsymbol{\Phi}_{i}^{e}\right\}_{j}\right)^{2}}{\left(\sum_{i=1}^{n}\left\{\boldsymbol{\Phi}_{i}^{a}\right\}_{j}\left\{\boldsymbol{\Phi}_{i}^{a}\right\}_{j}\right)\left(\sum_{i=1}^{n}\left\{\boldsymbol{\Phi}_{i}^{e}\right\}_{j}\left\{\boldsymbol{\Phi}_{i}^{e}\right\}_{j}\right)}$

The results demonstrate that certain combinations of modes may indicate damage, but when all modes are used, the indication of damage can be masked by modes that are not susceptible to damage.

Changes in mode shapes are more sensitive to local damage compared to changes in natural frequencies. However, using mode shapes also has some disadvantages. First, the damage is a local phenomenon and may not significantly influence the shapes of the first vibration modes, obtained from vibration tests on structures with large spans and, in addition, may be affected by the noise of the environmental loads or the position of the sensors.

Modal Curvature Difference (MCD) can also be evaluated, such as in Ndambi et al. [10], which indicate that derivatives of modal deformations, such as modal curvatures, are more sensitive to small perturbations and therefore can be used in damage detection.
Pandey et al. [11] demonstrate that absolute changes in the modal curvature may be a good indicator of damage in finite element models of beams. The curvature values are calculated from the modal shape displacement, using the center difference approximation for the displacement of point $i$ in the modal shape of mode $j$. The modal curvature is defined by Equation 3.

$\Phi_{(i, j)}{ }^{\prime \prime}=\frac{\Phi_{(i-1, j)}-2 \Phi_{(i, j)}+\Phi_{(i+1, j)}}{h^{2}}$

Where:

$\Phi_{(\mathrm{i}, \mathrm{j})}{ }^{\prime \prime}-$ modal curvature of the i-th point in the j-th mode;

$\Phi_{(\mathrm{i}, \mathrm{j})}$ - displacement of the modal shape of the i-th point in the $\mathrm{j}$-th mode;

$\mathrm{h}$ - distance between points $\mathrm{i}-1$ and $\mathrm{i}+1$;

i - measurement point;

j - vibration mode.

The location of the damage would be obtained by comparing the intact and damage structure modal curvatures. According to Dawari et al. [12], in damaged regions, the value of the modal curvature is significantly higher than those of other sites. Based on the values of modal curvature difference between damaged and intact structures, the location of damage can be identified.

Dawari et al. [12] report that the modal curvature difference (MCD) method was applied to simply supported and cantilever models. Numerical results demonstrate the effectiveness of the method in locating single and multiple damage scenarios in beams. Changes in modal curvatures were clearly observed in regions with damage.

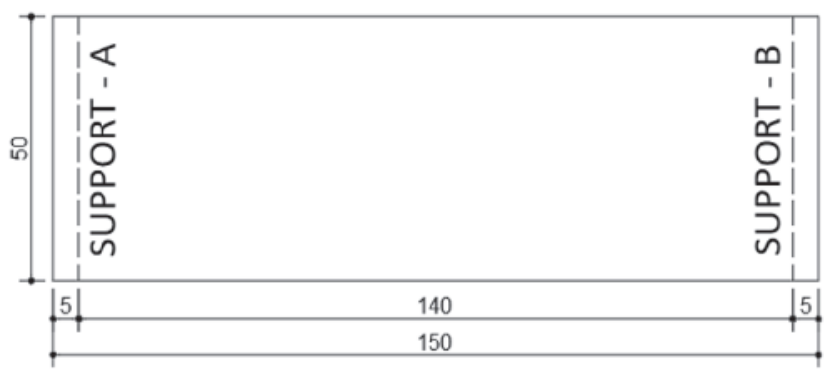

PLAN VIEW

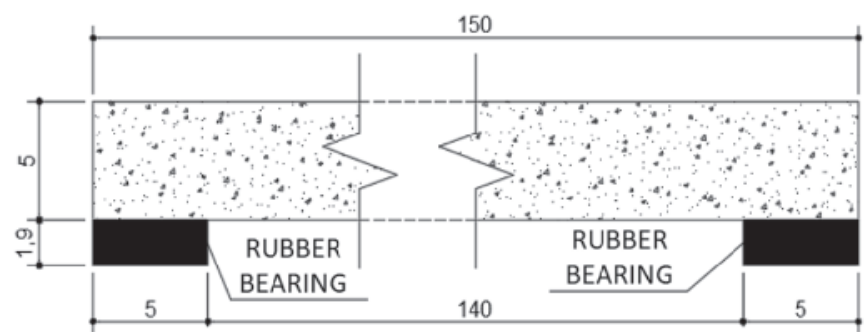

LONGITUDINAL SECTION

Figure 1

Geometry and contour conditions of the models (measured in centimeters) 


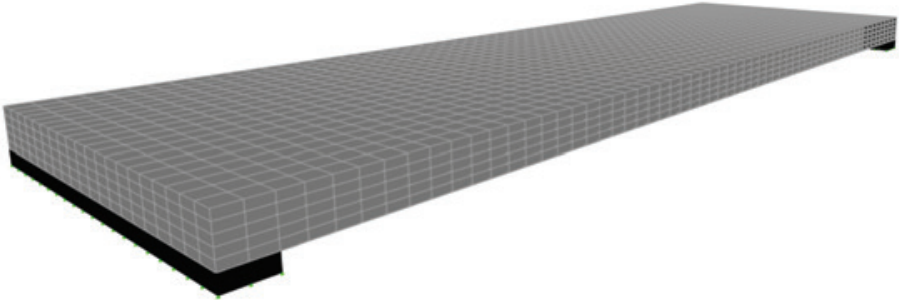

(A)

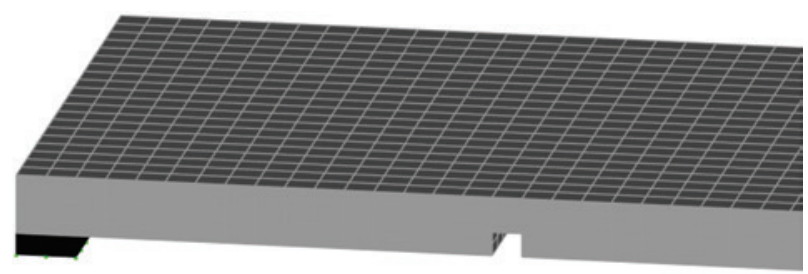

(B)

Figure 2

3D view of the numerical model - intact (a) and with damage (b)

In this study, the MCD method was implemented by means of displacements of the modal shape, extracted from the results of the numerical models.

The accelerations, velocities and displacements, collected in dynamic tests, are generally used as feedstock in modal analyses, damage detections and locations. However, some studies correlate the variation of amplitudes to the location of damages. Owolabi et al. [13] found that the Frequency Response Function (FRF) of the accelerations and displacements, underwent changes in the amplitudes of the natural frequencies.

Meredith et al. [14] investigated the possibility of applying the acceleration response of a simply supported beam subjected to a moving load to detect damages. It was found that the method is able to detect multiple cracks, however, the results are not clear. This method proved to be able to detect cracks with $10 \%$ of depth in a simply supported beam by means of the moving averages of the acceleration amplitude. Lotfollahi-Yaghin et al. [15] presented the location of damages in reinforced concrete beams from the variation in acceleration amplitude, in each natural frequency, through the function of Power Spectral Density (PSD). loannis [16] investigated the location of damage in an airplane propeller prototype. In the analysis of the acceleration data, it was observed that the indicators of damage are intensified at some points of the propeller. This occurs, therefore, the reflections of waves at the damaged region amplify the vibrations close to the damage. Kos et al. [17] monitored the modal parame- ters during fatigue tests on metal components of machines. The authors identified that, in addition to the natural frequency changes, the acceleration amplitudes suffered from alterations in the regions with damage. Note that, in the literature, the location of the damage is linked to the acceleration amplitude in the natural frequencies in functions in the frequency domain (FRF and PSD) This study determined the location of the damage through the application of the Modal Curvature Differences (MCD) method, through the modal curvature changes obtained from numerical models. In addition, an empirical formulation was developed for the location of damages based on variations of the acceleration amplitudes in the time domain.

It should be emphasized that, because it was a study based on numerical results, no noise influences and experimental errors were considered. Therefore, the application of the methods presented in experimental results may present inferior performance to those observed in this study.

\section{Numerical model and proposed formulation}

Three-dimensional numerical models were elaborated, representative of a simply supported slab (Figure 1), discretized in finite elements using the SAP $2000^{\circledR}$ computational package to analyze the natural frequencies, vibration modes and damage simulations along the span. The main goal was to evaluate the behavior by the MCD (Modal Curvature Difference) method and to develop an alternative

\section{Table 1}

Nomenclature and model description

\begin{tabular}{|c|c|c|c|c|}
\hline \multirow{2}{*}{$\begin{array}{l}\text { Nomenclature } \\
\text { model }\end{array}$} & \multirow{2}{*}{$\begin{array}{l}\text { Description damage } \\
\text { position } \\
(\mathrm{cm})\end{array}$} & \multirow{2}{*}{$\begin{array}{c}\text { Nomenclature } \\
\text { model }\end{array}$} & \multicolumn{2}{|c|}{ Description } \\
\hline & & & Cut $1(\mathrm{~cm})$ & Cut $2(\mathrm{~cm})$ \\
\hline B1-COR-5 & 5.0 & B1-2COR-105-5 & 5.0 & 105 \\
\hline B1-COR-15 & 15.0 & B1-2COR-105-15 & 15.0 & 105 \\
\hline B1-COR-25 & 25.0 & B1-2COR-105-25 & 25.0 & 105 \\
\hline B1-COR-35 & 35.0 & B1-2COR-105-35 & 35.0 & 105 \\
\hline B1-COR-45 & 45.0 & B1-2COR-105-45 & 45.0 & 105 \\
\hline B1-COR-55 & 55.0 & B1-2COR-105-55 & 55.0 & 105 \\
\hline B1-COR-65 & 65.0 & B1-2COR-105-65 & 65.0 & 105 \\
\hline B1-COR-75 & 75.0 & B1-2COR-105-75 & 75.0 & 105 \\
\hline
\end{tabular}


tool, called the ASD Method (Acceleration Summation Difference). The three-dimensional model, consisting of solid elements, represents a concrete slab, with rubber supports, discretized using elements of $25 \mathrm{~mm} \times 25 \mathrm{~mm} \times 10 \mathrm{~mm}$ and $25 \mathrm{~mm} \times 25 \mathrm{~mm} \times 18 \mathrm{~mm}$, respectively. At the base of the elastomeric bearing, the displacements of the nodes in the three directions were restricted, as shown in Figure 2.

The damage simulation was introduced excluding the solids from the model and varying its location along the span. Also, in Figure 2 , the induced damage is indicated in the model, simulating a cut of $2 \mathrm{~cm}$ of depth to $40 \mathrm{~cm}$ of the left support.

The modulus of elasticity of the rubber and the Poisson's coefficients of rubber and concrete were, for all models, $E_{r}=25(\mathrm{MPa})$ and $n_{r}=0.45$ and $n_{c}=0.20$, respectively. The modulus of elasticity of the concrete was adopted as $33.300 \mathrm{MPa}$, a value derived from a series of tests conducted by Silva [18], which aimed to validate the methodology for damage identification using numerical methods, and confirm it based on experimental results.

Three different numerical models were elaborated, being one intact, one with a damage and, finally, one that simulated the behavior with 2 localized damages. Thus, the MCD method was applied and tests

\section{Table 2}

Comparison between the natural frequencies of the intact and damage models

\begin{tabular}{cccc}
\hline \multirow{2}{*}{ Mode } & \multicolumn{3}{c}{ Model $-\mathbf{f}_{\mathbf{n}}(\mathbf{H z})$} \\
\cline { 2 - 4 } & Intact & $\mathbf{1}$ cut & 2 cuts \\
\hline 1 - Vertical & 39.3 & $37.1(-5.6 \%)$ & $35.4(-9.9 \%)$ \\
2- Transversal & 83.7 & $84.1(+0.5 \%)$ & $84.5(+0.9 \%)$ \\
3 - Longitudinal & 84.7 & $85.0(+0.3 \%)$ & $84.9(+0.2 \%)$ \\
4 - Vertical & 256.7 & $255.6(-0.4 \%)$ & $254.2(-1.0 \%)$ \\
\hline
\end{tabular}

were performed with the empirical method proposed in this work (ASD). The models with one damage were analyzed individually with a damage every $10 \mathrm{~cm}$, from the middle of the span to the left support. Then, a second, fixed damage was introduced, $105 \mathrm{~cm}$ from the left support in each of them. Table 1 lists the nomenclature and position of the cuts for the analyses performed, where the position of the damage is always referenced from the left support axis. The dynamic loading simulations were performed with the application of an impulsive load with a maximum force of $1 \mathrm{kN}$,
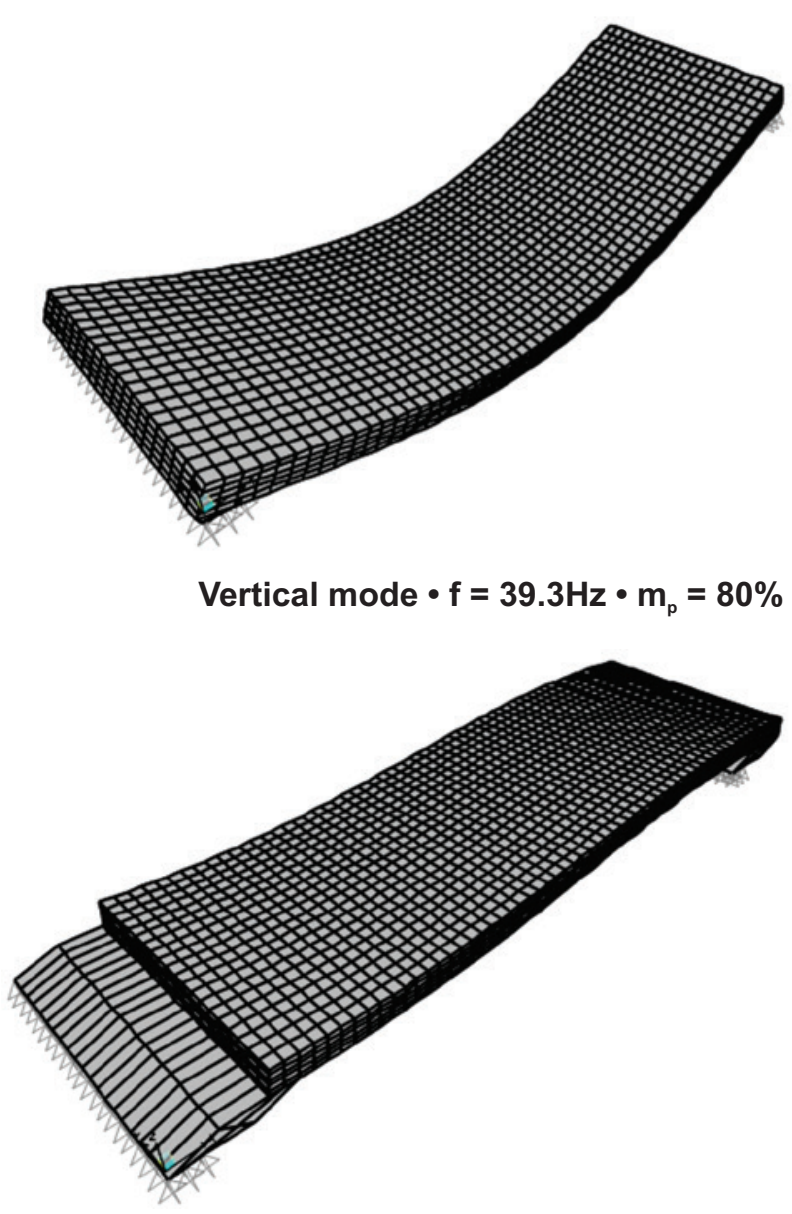

Longitudinal $\operatorname{mode} \cdot f=84.7 \mathrm{~Hz} \cdot m_{p}=99 \%$

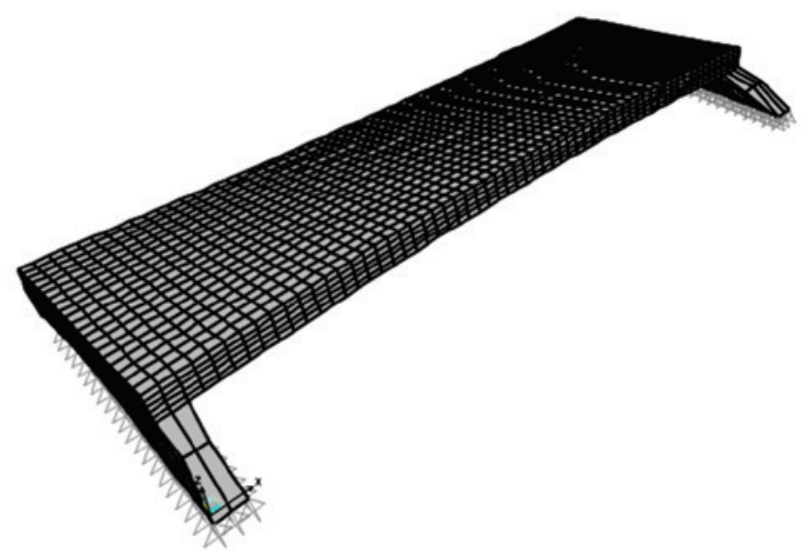

Transversal $\operatorname{mode} \cdot f=83.7 \mathrm{~Hz} \cdot \mathrm{m}_{\mathrm{p}}=96 \%$

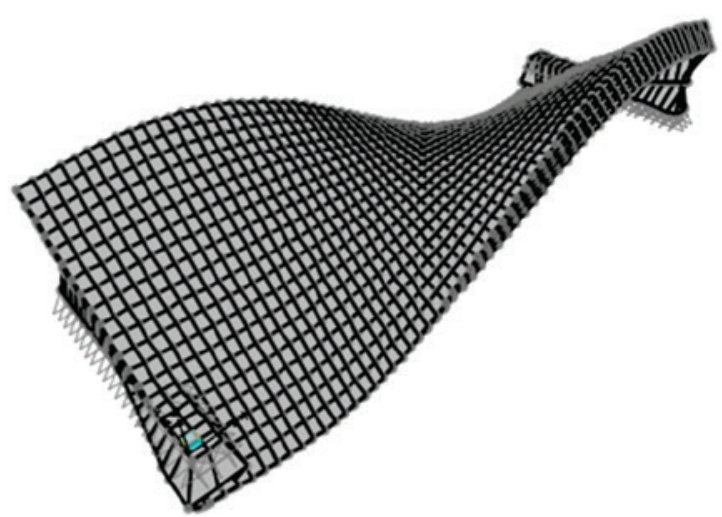

Vertical mode $\bullet f=256.7 \mathrm{~Hz} \cdot m_{p}=17 \%$

Figure 3

Modes of vibration and modal mass participation of the intact numerical model 


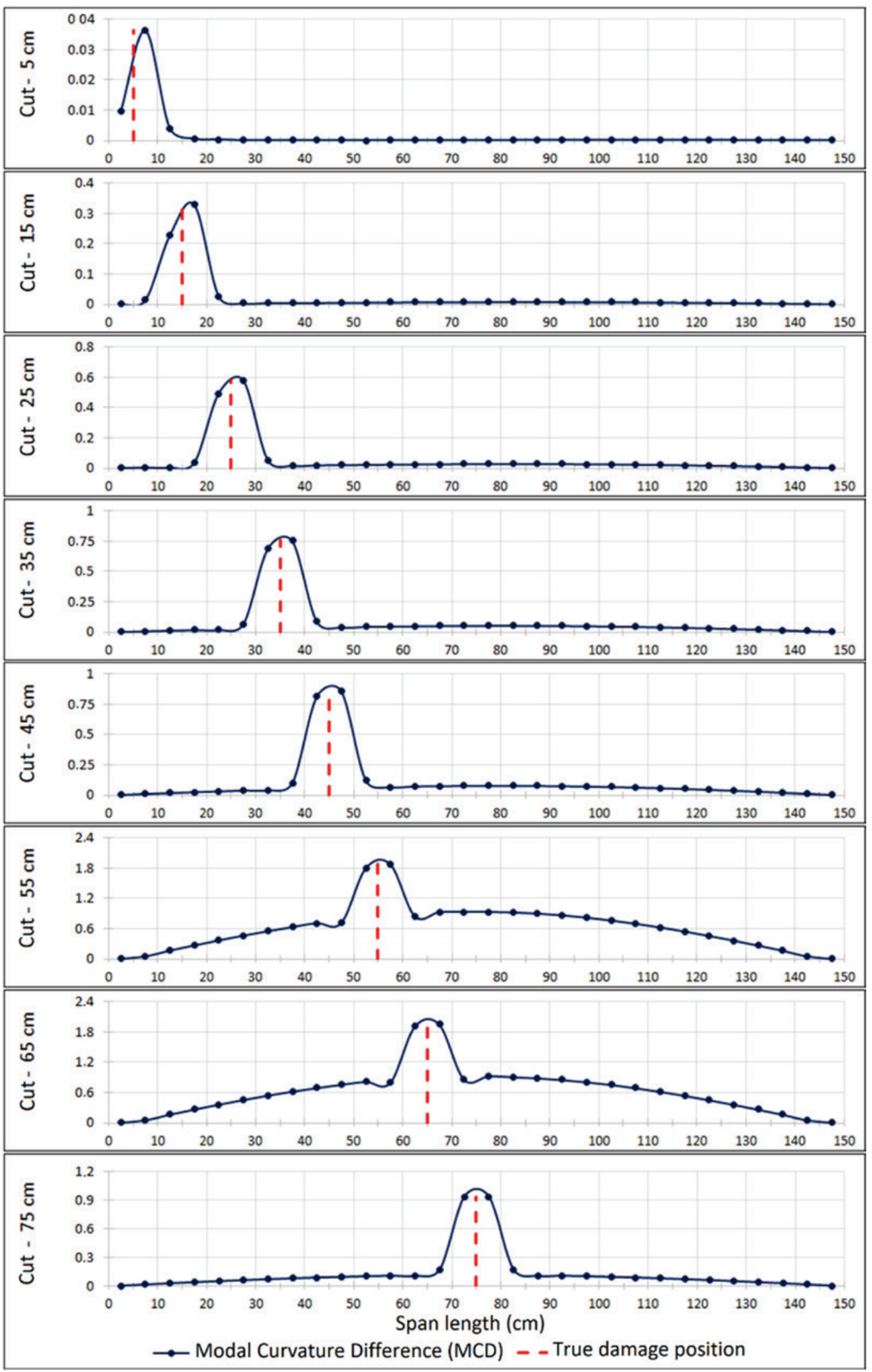

Figure 4

Identification of a single damage with MCD method 
in the middle of the span, by means of a time-history function. Then, the acceleration data, derived from the dynamic response of the structure, were extracted in 30 points distributed along the span, with steps of 0.001 seconds, equivalent to an acquisition rate of $1000 \mathrm{~Hz}$.

\section{Modal analysis and identification of damages and their position}

The natural frequencies, vibration modes and modal mass participation of the intact numerical model are presented in Figure 3. It is emphasized that the number of vibration modes presented was stipulated according to modal mass participation, using as stopping criterion the accumulated value of at least $95 \%$ of the participating mass in each direction. The natural frequencies of all models are shown in Table 2, clearly showing the reduction of their value in relation to the first mode of vibration when compared to the intact model with those with damages. In relation to the transverse and longitudinal modes, a slight increase in the natural frequencies was observed, this happens because the alteration of the geometry (introduction of the fault) has little influence on the stiffness in these directions and, on the other hand, the mass reduction contributes to the increase in natural frequency.

The results of numerical simulations for single and multiple damage location at different points in the model are presented below. In addition to the application of the Modal Curvature Difference (MCD) Method, an empirical expression based on the sum of the accelerations was proposed in order to develop an alternative methodology.

The application of MCD was restricted only to the first vertical mode since, in the previous simulations, it was observed that the participation of modal mass was concentrated in few modes of vibration and, in the models adopted, the induced damage little affected the transverse and longitudinal modes. Figure 4 presents the graphs of the differences of modal curvature, from the application of the MCD method in the models with a damage. These graphs show that, although the damage dimensions were identical, the amplitude of the modal curvature difference increased as the damage location approached the center of the span, except when the damage was exactly at the center of the span. The MCD variation along the span may interfere on the analysis of the location of multiple damages, since damage located near the center of the span may mask another that is close to the support. Figure 5 shows the amplitude variation factor according to the position of the damage, in the models analyzed. This factor is the quotient between the amplitude of the peaks that indicate the location of the damage along the span and the peak amplitude for the damage located near the support, representing the variation of the sensitivity of the method along the span.

In order to analyze the behavior of the MCD method in the occurrence of simultaneous damages, other simulations were carried out by adopting a fixed damage at $105 \mathrm{~cm}$ from the left support simultaneously to another one with variable position along the span. The results of this analysis are presented in Figure 6.
From the models with damages induced along the span and used in the application of the MCD method, we sought a direct relation between the data of vibration (accelerations, velocity and displacements) and the damage location. As an example, in some studies, such as those developed by Meredith [14] or Owolabi et al [13], a change in the amplitude of accelerations and displacements in FRFs (Frequency Response Function) were observed. Based on the change in acceleration amplitude in the region close to the damage, we determined, from tests of several hypotheses, an empirical formulation capable of identifying the location of damages at any point along the span of the simply supported structure. Among the alternatives analyzed, we can cite the difference between acceleration peaks, the subtraction of an acceleration curve from the other and the difference between the RMS values, however, none of them presented consistent results. The most relevant result was obtained by the difference of the acceleration summation difference (ASD), obtained from the dynamic response of the structure for a given excitation, in a known time interval, starting the summation from the first peak of the impulsive signal. Figure 7 shows the acceleration graph over time, obtained from the numerical simulation of an impulsive excitation, and the evolution curve of the sum of the accelerations. It is observed that the sum of the accelerations covers practically the entire interval of oscillation of the impulsive signal. This helps to emphasize the location of the damage, since more data of the acceleration amplitudes will be used, increasing the accumulated value of the amplitude differences. When comparing the absolute sum of the accelerations along the span between the intact and damaged models, a change was identified in the damage region, and it is possible to use the acceleration summation difference (ASD) as an indication of its presence (Figure 8). In order to improve the graphical visualization of the damage location, the result of the difference was squared, making all values positive in the graph scale and increasing the magnitude of the damage indicator. As a result, we obtained the empirical formulation expressed by Equation 4.

$\operatorname{ASD}_{(j)}=\left(\sum_{t_{i}}^{t_{f}}\left|a_{j-i n t}\right|-\sum_{t_{i}}^{t_{f}}\left|a_{j-d a m}\right|\right)^{2}$

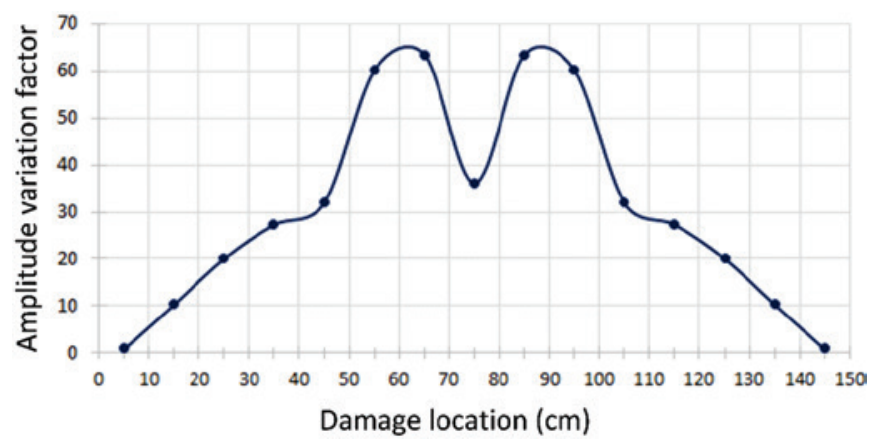

Figure 5

Amplitude variation factor of MCD method versus the position of the damage in the model with only one damage 


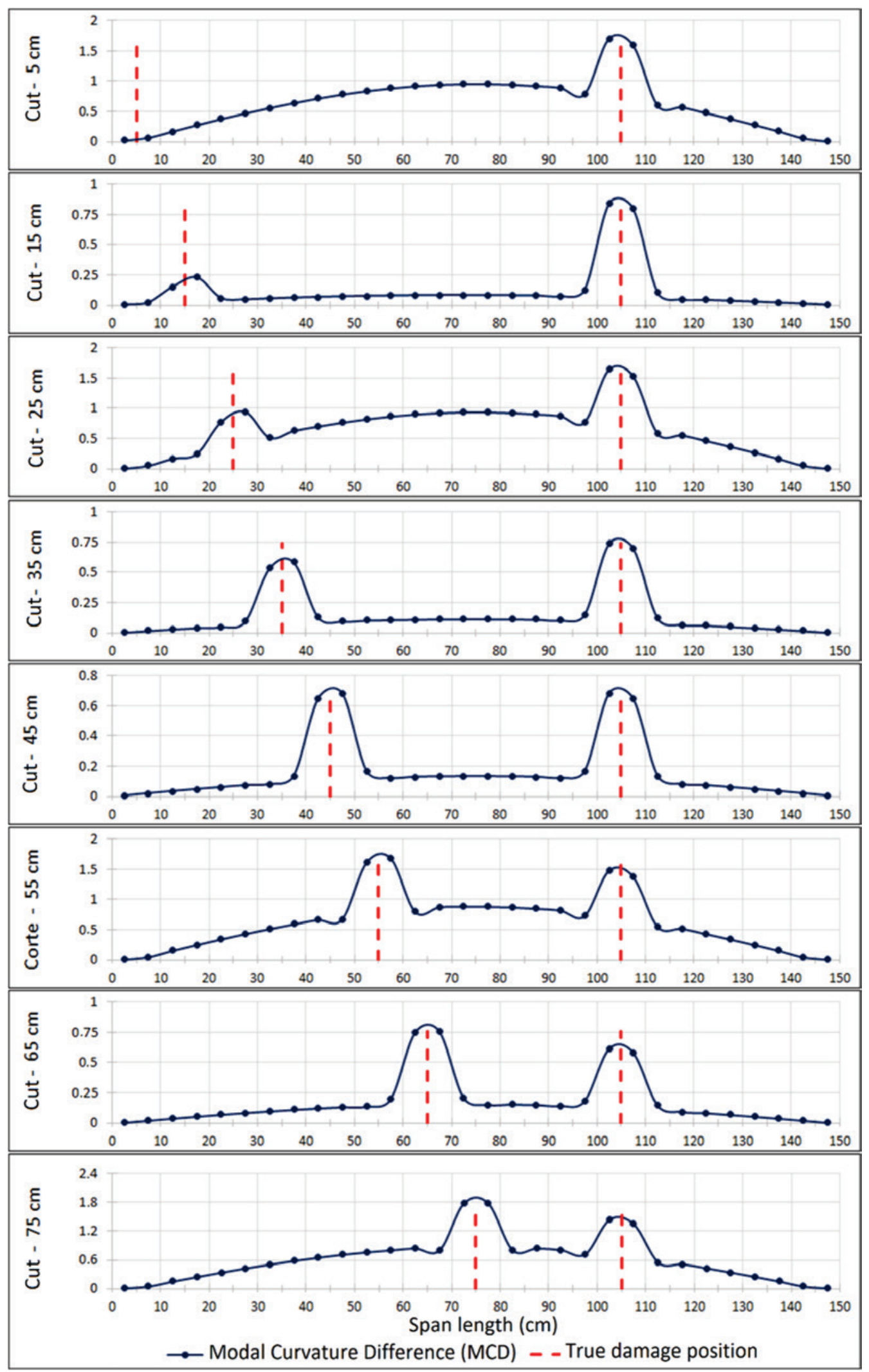

Figure 6

Identification of multiple damages with MCD method 


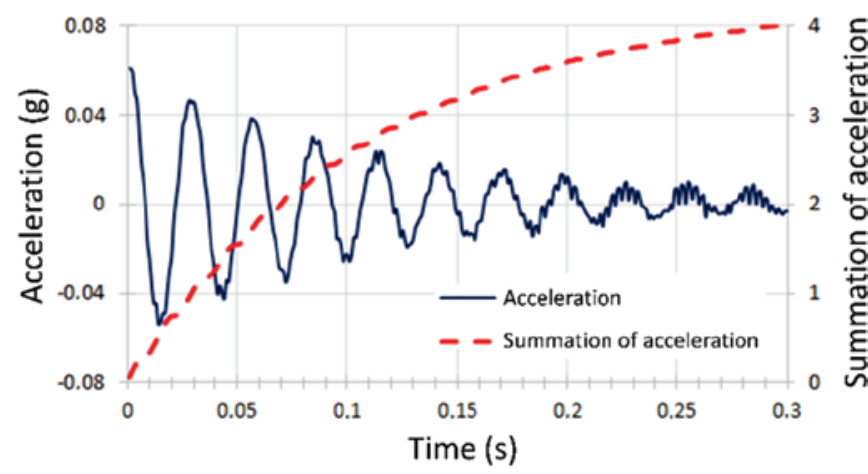

\section{Figure 7}

Acceleration graph over time and curve of the sum of the accelerations

Where:

$\mathrm{ASD}_{(j)}$ : square difference of the acceleration sum at the j-th point; $\left|\mathrm{a}_{\mathrm{i} \text {-int }}\right|$ : absolute value of acceleration in the intact model at the j-th point;

$\left|a_{j-d a m}\right|$ : absolute value of acceleration of the model with damage at the j-th point;

$\mathrm{t}_{\mathrm{i}}$ : initial time considered from the peak of acceleration of the impulsive signal;

$\mathrm{t}_{\mathrm{f}}$ : final time with the same interval in all analyses $(\Delta t=0.3 \mathrm{~s})$.

It can be said that one of the characteristics that differ the ASD method from the others in the literature is its ease of computational implementation, since its calculation procedure is based only on the data of vibration over time, dispensing the determination in the domain of the frequency or vibration modes to obtain their results.

To validate the proposed relationship, the models and considerations previously adopted were used, when applying the MCD method, with one and two damages along the span. Figure 9 shows the graphs obtained with the application of the ASD method in models with a single damage. As with the MCD method, varying the differences in the sum of the accelerations may interfere on the analysis of the location of multiple damages depending on where the damage is located. Figure 10 shows the ASD amplitude variation factor according to the position of the damage. Finally, the performance of the ASD method in the occurrence of multiple damages was analyzed and the results are presented in Figure 11.

Both MCD and ASD, developed herein, presented similar responses for the analysis of the models with only one damage. Both methods presented satisfactory precision in the location of the damage, however, it should be emphasized that in both methods the accuracy of damage location is related to the distance between analyzed points of the structure in which the method was applied. Therefore, the peaks in the graphs indicate that the points (of the finite element mesh) analyzed are close to the damage, however, in an experimental simulation, the position of the instrumentation can determine the success of the analysis and location of the existing damage: the spacing between the sensors would directly influence the precision of the location, because the sensor closest to the damage will have the largest difference in the acceleration amplitude.

Comparing the graphs obtained through MCD and ASD, it can be observed that the curves resulting from the use of MCD show the location of the damage more clearly, without major changes in the other points along the span. In the curves from the application of the ASD method, small oscillations were observed at points distant from the damage, without prejudice to the analysis (Figure 12).

As shown in Figure 5 and Figure 10, the amplitudes of the peaks, which indicate the location of the damage, vary according to its position. The further away from the support region, the higher the peak value. This behavior was verified in both methods studied. In the results of the MCD method, a maximum variation of 63 times was verified, comparing the peak values of a damage close to the support with one located at the central region of the span. Nevertheless, analyzing the results of the ASD method, this value was even higher, about 445 times. In this way, the occurrence of damage close to the support can be masked by another located in the central region. Hence the importance of additional analyses to verify the behavior of the two methods in the occurrence of simultaneous damages.

In the results obtained with the MCD method, it was observed that, despite the amplitude variation, the peaks are clear and correctly indicate the location of the two damages, except in the first case, since the peak indicative of the damage located $5 \mathrm{~cm}$ from the support was masked by the peak referring to another damage, of greater amplitude.

On the other hand, the results of the ASD method presented inferior performance in the location of multiple damages. As expected, due to the quadratic expression proposed, a large variation in peak amplitudes was found, making it difficult to identify the two damages. This limitation was observed when one of the damages was very close to the support (situation with cut at $5 \mathrm{~cm}$ ) and when one of the damages is very close to the center of the span (situations with cut at 65 and $75 \mathrm{~cm}$ ). Figure 13 shows the comparison between the results of the two methods for the situation with cuts at 75 and $105 \mathrm{~cm}$. In the MCD method, despite the amplitude variation, the two peaks

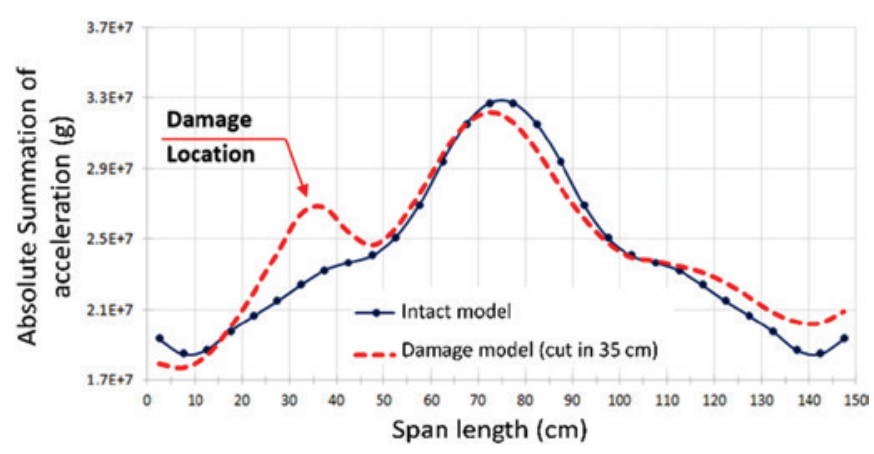

Figure 8

Comparison of the absolute sum of the accelerations obtained from the model with only one damage 


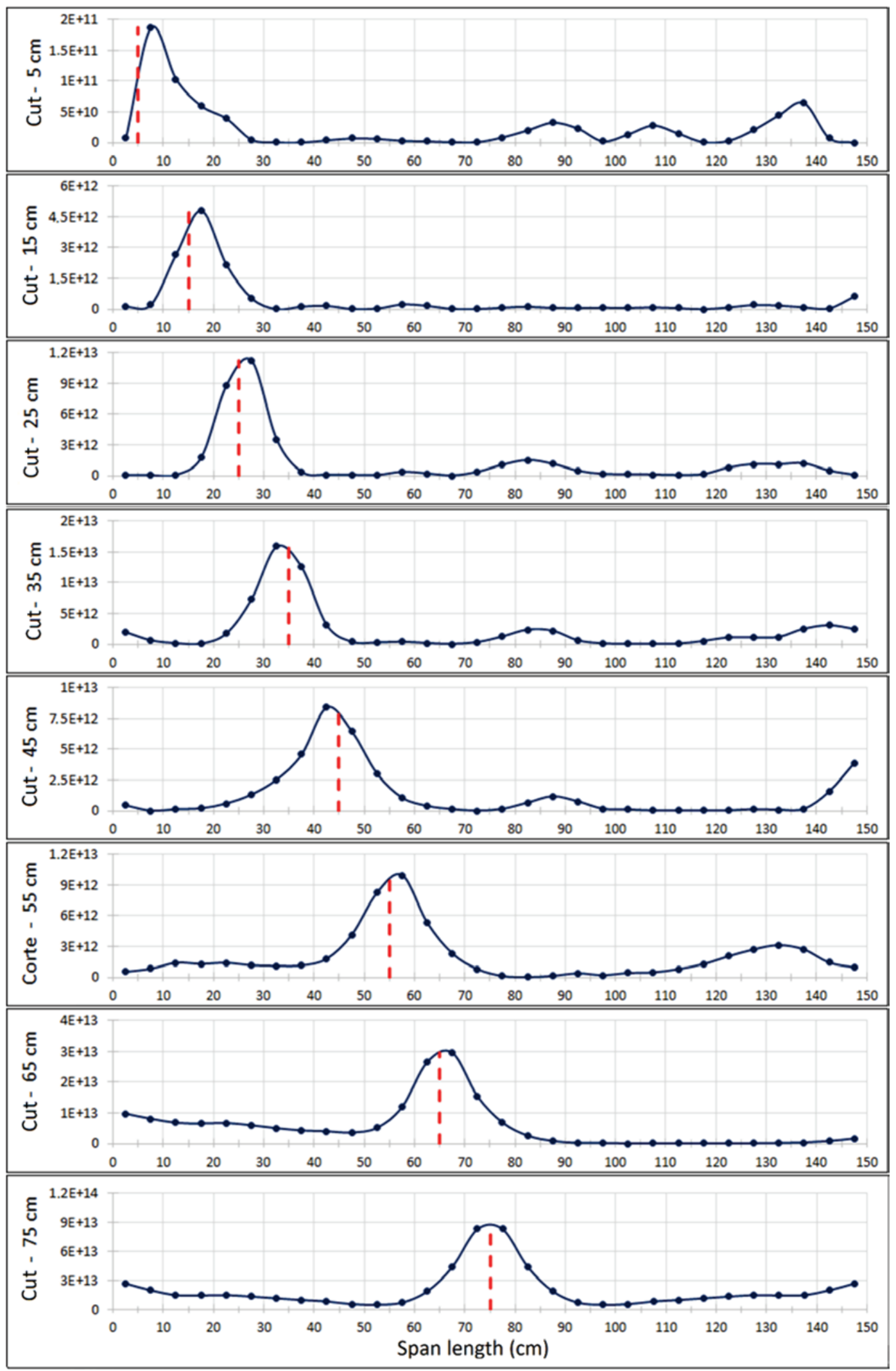

Figure 9

Identification of a single damage with ASD method 


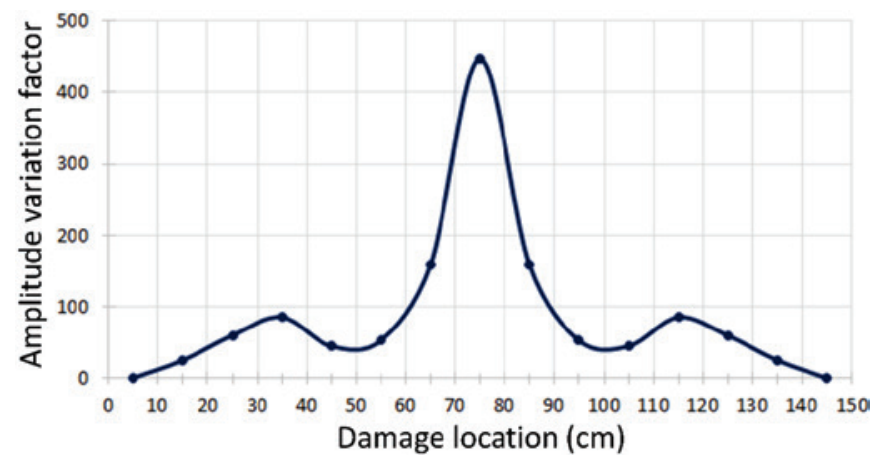

Figure 10

Amplitude variation factor of ASD method versus the position of the damage in the model with only one damage

are clear and the location is correct. In contrast, in the ASD method, the amplitude of the damage located at $75 \mathrm{~cm}$ (middle of the span) masks the other damage.

In general, the two methods proved to be efficient for this specific problem in locating a damage in a simply supported structure. However, the results of analyses of the models with two damages revealed some limitations, especially in the use of the ASD method.

\section{Conclusion}

This work proposed an empirical formulation capable of locating damages in simply supported concrete structures, called Acceleration Summation Difference (ASD). It is based on the difference of acceleration amplitudes between structures intact and with damage. In addition, a comparison of the damage location results was done with the method already established in the literature, Modal Curvature Difference (MCD). The main conclusions of the study are:

- The MCD method indicated good results in damage localization, even though it was applied only to the first vertical mode. The application to the other modes was not necessary, since the modal mass participation was concentrated in few modes of vibration and, in the models used, the induced damage affected little the transverse and longitudinal modes;

- The response of the MCD method varies according to the position of the damage along the span. In the models used, the amplitude of the MCD peak increased as the location of the damage was closer to the center of the span. This variation was evident in the application of the method in the location of multiple damages, because the damage located near the center of the span masks the damage close to the support;

Damage location, along the span of the model, could be determined by applying the ASD method. However, as in the MCD method, the variation in the ASD response interferes with the analysis of the location of multiple damages and in the evaluation of the degree of intensity of the dama- ge, because in these cases, damages of the same intensity generate different responses. It should be noted that the response variation of the ASD method is higher than that of the MCD and, consequently, its efficiency in determining multiple damages is lower;

- In the application of both methods, it was observed that the precision in the detection is correlated with the distance between the points analyzed. Therefore, for the experimental application of these methods, the distance between the acceleration transducer should be linked to the desired precision;

- The ASD method can be used as an auxiliary tool in damage identification and location analysis and has proved to be a simpler method, of easy application, because it works with the pure acceleration data without the need for analysis in the domain of frequencies and the determination of the modal shape;

It is emphasized that the success of the ASD method requires that the excitation be exactly the same: intensity and location of application, whereas the MCD method does not require the control of the intensity and the positioning of the application of excitation, allowing the use of environmental vibrations.

- The relationship found refers to simply supported structures, so its use in distinct structural arrangements must be verified.

\section{Acknowledgements}

The authors thank the Department of Structural and Geotechnical Engineering of the Polytechnic School, University of São Paulo, for the loan of the infrastructure for the accomplishment of numerical simulations with the ARTEMIS computational package.

\section{References}

[1] NÓBREGA, P. G. B. Análise dinâmica de estruturas de concreto: estudo experimental e numérico das condições de contorno de estruturas pré-moldadas. Tese (Doutorado) - Escola de Engenharia de São Carlos, Universidade de São Paulo. 2004.

[2] SOHN, H., C. FARRAR, R., HEMEZ, F. M., SHUNK, D. D., STINEMATES, D. W., NADLER, B. R. and CZARNE$\mathrm{CKI}, \mathrm{J}$. J. A review of structural health monitoring literature: 1996-2001, Los Alamos National Laboratory, Los Angeles, 2004.

[3] RYTTER, A. Vibration Based Inspection of Civil Engineering Structures. PhD thesis, Department of Building Technology and Structural Engineering, Aalborg University, Denmark, 1993.

[4] ADAMS, D. E. Health Monitoring of Structural Materials and Components: Methods with Applications, 1st ed. Hoboken, 2007.

[5] PEETERS, B. System identification and damage detection in civil engineering. $\mathrm{PhD}$ thesis - Katholieke Universiteit Leuven, Belgium, ISBN 90-5682-274-8. 2000. 


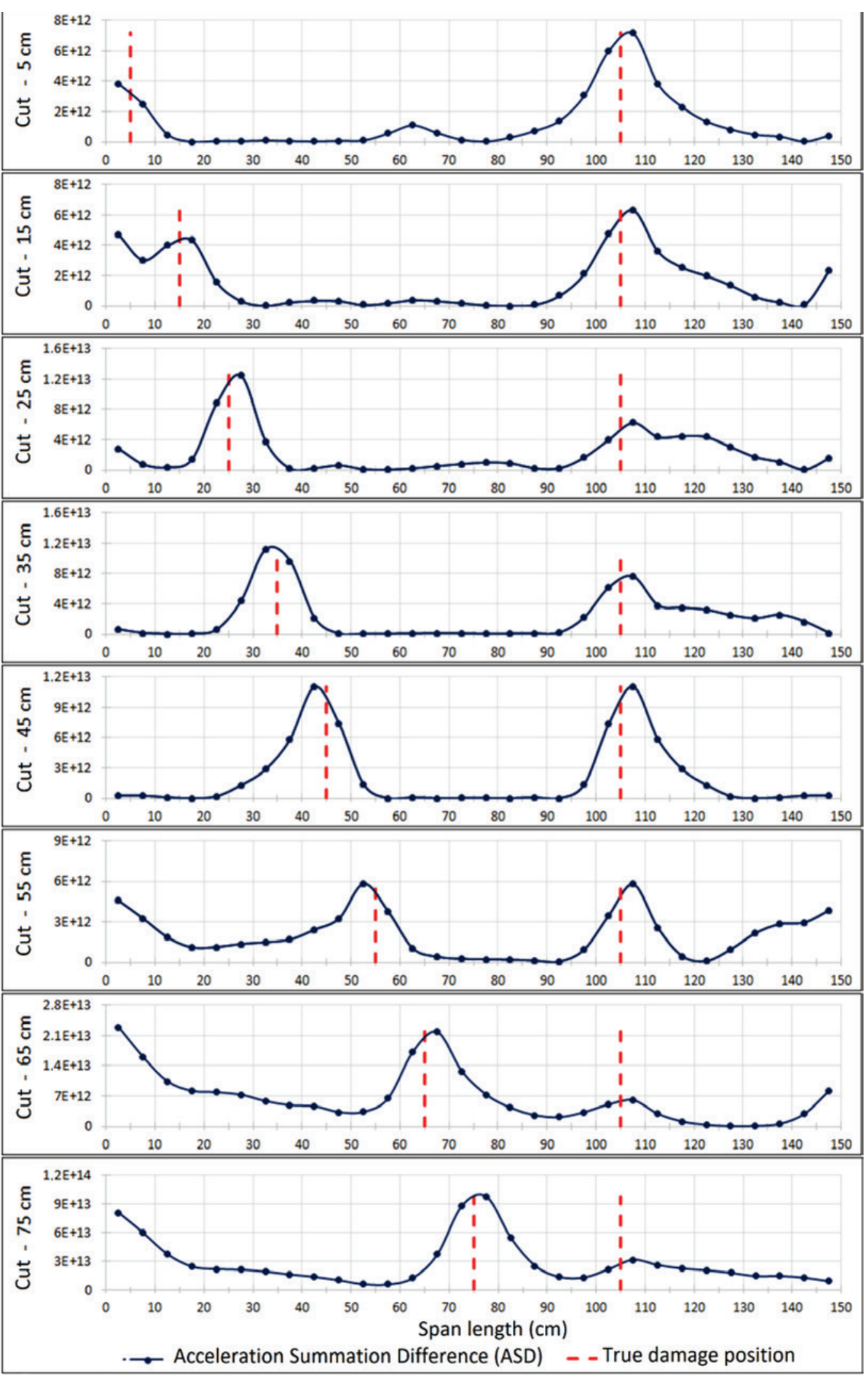

Figure 11

Identification of multiple damages with ASD method 


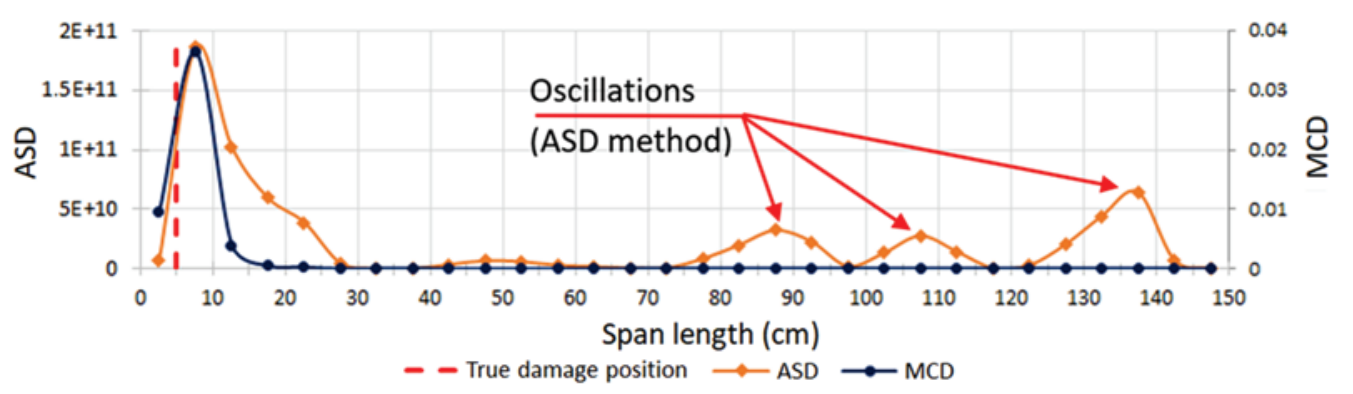

Figure 12

Comparison of the results obtained by ASD and MCD methods for the model with only one damage

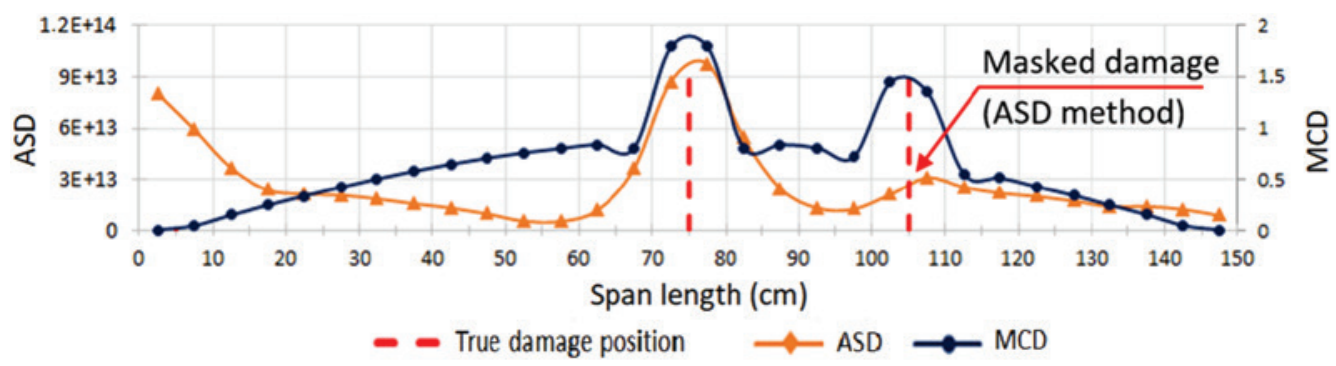

Figure 13

Comparison of the results obtained by ASD and MCD methods for the model with two damages

[6] DOEBLING, S. W., FARRAR, C. R., PRIME, M. B., and SHEVITZ, D. W., "Damage Identification and Health Monitoring of Structural and Mechanical Systems from Changes in Their Vibration Characteristics: A Literature Review," Los Alamos National Laboratory Report LA13070-MS, 1996.

[7] ALLEMANG, R.J.; D.L. BROWN. A Correlation Coefficient for Modal Vector Analysis. Proceedings of the 1st International Modal Analysis Conference, pp. 110-116, Orlando, Florida, USA. 1982.

[8] ALLEMANG, R.J. The Modal Assurance Criterion - Twenty Years of Use and Abuse, SOUND AND VIBRATION/ AUGUST 2003

[9] LIEVEN, N. e EWINS, D. J. Spatial correlation of mode shapes, the coordinate modal assurance criterion (comac), Proc. Of 6th International Modal Analysis Conference. 1988.

[10] NDAMBI, J.M., VANTOMME, J. e HARRI, K. Damage assessment in reinforced concrete beams using eigen frequencies and mode shape derivatives. Engineering Structures, 501-515. 2002.

[11] PANDEY, A.K., BISWAS M. e SAMMAN, M.M. Damage detection from changes in curvature mode shapes. Journal of sound and vibration, 145(2). 1991.

[12] DAWARI, V. B e VESMAWALA, G. R. Structural damage identification using modal curvature differences. Journal of Mechanical and Civil Engineering. ISSN, 1678-1684. 2013.

[13] OWOLABI, G.M.; SWAMIDAS, A. S. J.; SESHADRI, R. Crack Detection in Beams using Changes in Amplitudes and Frequencies of Frequency Response. Journal of Sound and Vibration, 265(1), 1-22. 2003.

[14] MEREDITH, J., GONZALEZ, A. and HESTER, D. Empirical mode decomposition of the acceleration response of a prismatic beam subject to a moving load to identify multiple damage locations. Shock and Vibration 19: 845-856. 2012.

[15] LOTFOLLAHI-YAGHIN, M. A., SHAHINPAR, R. e AHMA$\mathrm{DI}, \mathrm{H}$. Dynamic behaviour of damaged reinforced concrete beams and application of white noise analysis to crack detection. Journal of the South African Institution of Civil Engineering, vo.I 51, no 2, 2-10. 2009.

[16] IOANNIS, G.T. Advanced Processing of Collocated Acceleration Signals in Symmetric Beam-Like Structures With Applications to Damage Detection in a Propeller. Journal of Intelligent Material Systems and Structures, vol. 22. 2011.

[17] KOS, V. P., SLAVIL, J. e BOLTEZAR, M. Fatigue Damage for Sweep-Sine and Random Accelerated Vibration Testing. Hindawi Publishing Corporation - Advances in Mechanical Engineering - Article ID 340545. 2014.

[18] SILVA, R.L. Identificação e localização de danos em estruturas de concreto por meio de análise modal, experimental e numérica. Dissertação (Mestrado) - Universidade Estadual de Campinas. 2018. 